\title{
Patients' Perspectives on What Makes a Better Care Experience While Undergoing Treatment for Oropharyngeal Dysphagia Secondary to Head and Neck Cancer
}

\author{
Martin Checklin ${ }^{1}$ (D) Jessica Bain ${ }^{1} \cdot$ Lucy Bath $^{1} \cdot$ Kate Lethbridge $^{1}$
}

Received: 12 March 2019 / Accepted: 7 November 2019 / Published online: 20 November 2019

(c) Springer Science+Business Media, LLC, part of Springer Nature 2019

\begin{abstract}
Patients' perceptions on what makes a better care experience for head and neck cancer (HNca) have not been widely sought. Patients' perceptions can play a crucial role in shaping quality care and client involvement. To investigate patients' perspectives on what makes a better care experience while undergoing rehabilitation for oropharyngeal dysphagia secondary to $\mathrm{HNca}$. Qualitative data were collected in the form of semi-structured interviews from eight patients after they had undergone rehabilitation for HNca. The data were thematically analysed by two researchers independently. Six themes, plus subthemes, were identified. These themes were Supportive network is essential; Reassurance from staff professionalism; Access to service; Using own motivation and resilience; Receiving the right information and Ongoing shock and adjustment. Results are discussed in context of the literature and clinical implications and future research are recommended. Collation of patients' perspectives is valuable to increase insight into what makes a better rehabilitative journey for patients with HNca. Rehabilitation that is holistic, specialised and patient-specific is highly valued by patients with HNca.
\end{abstract}

Keywords Patients' perspectives · Rehabilitation · Dysphagia $\cdot$ Head and neck cancer · Oncology $\cdot$ Deglutition and deglutition disorders

\section{Introduction}

There is much literature surrounding the patient experience of living with head and neck cancer (HNca). Patients have been found to experience many difficulties with eating and drinking with identified personal themes of disruption to daily life and worries about the future [1]. Even once treatment is completed, patients continue to struggle with eating and drinking [2] and when challenged with dysphagia, a change in confidence and self-esteem occurs [3]. Patients were found to have changed the type of food they ate and how they ate it as a result of their dysphagia. Patients were

The work was conducted at Speech Pathology and Dietetics, Epworth Rehabilitation and Mental Health, Epworth Healthcare, 32 Erin Street, Richmond, VIC, 3121, Australia.

Martin Checklin

Martin.checklin@epworth.org.au

Speech Pathology and Dietetics, Epworth Rehabilitation and Mental Health, Epworth Healthcare, 32 Erin Street, Richmond, VIC 3121, Australia able to identify how these physical swallowing changes also impacted their lifestyles. Their family routines and meal environments had to change alongside their reduced oral hygiene and fear of embarrassment in social situations [3, 4]. Their perception of food including appreciation and enjoyment of food had changed, affecting them emotionally and contributing to reduced psychological wellbeing $[4,5]$. They reported uncertainty regarding prognosis of symptoms or reoccurrence and recognised the need for support networks to help them cope with their symptoms [6]. Another reported experience for this population was that patients felt there was little time to ask questions throughout their treatment period and they did not receive as much information about their situation as they felt they needed [1]. Although these studies provide important information on the experiences of patients who have undergone $\mathrm{HNca}$ and treatment, there is however, limited research regarding 'what we are going to do' about these documented patient experiences [7].

Some recommendations from the research include ensuring a multidisciplinary approach inclusive of nutrition and psychology assessments and dysphagia strategies to attempt to cover the complexity of these patients' eating and drinking 
difficulties [6]. Messing, Ward [8] explored implementation of a multidisciplinary pathway to attempt to improve patient accessibility and service sustainability. Whilst concluding that a pathway can have positive clinical outcomes, they found that it is a complex process which requires significant time and resources. They also acknowledged having limited data from the patient perspective and identifying the need for research to investigate and consider the patients' experience.

In the current research of treatments for dysphagia associated with HNca, Cousins, MacAulay [9] noted how most treatments were based on clinician's objective measures rather than the patients' perspective of their own functional measures. Similarly when looking at communication changes in HNca, Nund [4] found that cancer survivors' perceptions of their reported outcomes did not match clinicians' impairment-based assessment. They suggested a need for research to move towards capturing the patient perspective to fully understand the extent of functional outcomes of $\mathrm{HNca}$ treatment. Obtaining patients' perceptions is highly important as responding to patients' perceptions is a key attribute to providing quality care and can increase user involvement [10]. This study seeks to extend these ideas by investigating the patient's perspective of their rehabilitation stage post HNca.

\section{Aim}

To investigate patients' perspectives on what makes a better care experience while undergoing rehabilitation for oropharyngeal dysphagia secondary to HNca.

\section{Methodology}

Recruitment occurred in a large Australian not-for-profit private multidisciplinary rehabilitation setting. The current practice within this hospital is that patients are seen by their surgical and acute Allied Health team as inpatients, receive their concurrent radio and/or chemotherapy either internally or externally (if required) and are then referred to the rehabilitation outpatient program if ongoing outpatient Allied Health services are needed. Local ethics approval had been granted. Purposeful sampling was used to select adult participants who had a medical diagnosis of HNca as per the medical file, had a degree of dysphagia they had been treated for and cognitive ability to provide consent and data. Exclusion criteria included anyone who had recurrence during their rehabilitation phase and anyone who could not participate in an interview. Purposeful sampling also allowed selection of participants who had treatment with different clinicians, enabling an evaluation of the experience of a service, as opposed to the experience of an individual.
Interviews occurred after mutual agreement between clinicians and participants that their active rehabilitation had ceased therefore allowing a retrospective report on their experience. Participants were approached face-to-face at the end of the rehabilitation by one of the authors in the research team and asked to participate.

Semi-structured in-depth interviews, with open-ended questions, were used to collect the data (Appendix 1). The interview questions focused on the elements of care that worked well for the participants' experience and which parts of their care could be completed differently. The interviewer was female and an experienced qualitative interviewer, who worked as a speech pathologist in the location of the study, but had never been involved in the participants' care. The interviewer did not participate in other aspects of the project and was blinded to codes which were identified during the analysis stage. The participants only knew the interviewer as the interviewer and rapport was built in a pre-discussion phone call and later on prior to the interview taking place. Interviews occurred either in the rehabilitation centre, the participants' home or via videoconferencing. One participant required an interpreter. All participants were able to communicate verbally and all interviews were audio recorded.

During the interview, participants were given a Symptoms Checklist (Appendix 2). The rationale for this was to identify which symptoms were managed well and which symptoms could have been managed better to enable guidance on improving clinical care. The symptoms in the checklist have been well documented in the literature [9, 11-14]. The symptoms were then tabulated into which symptoms participants experienced and which symptoms were well managed or not.

Interviews were then transcribed by an external transcription company and checked by a member of the research team on return, not participants. Open coding was completed using NVIVO (NVivo qualitative data analysis Software; QSR International Pty Ltd. Version 10, 2012.). The primary coder (JB) had received training in coding and NVIVO and the second coder (MC) had experience in coding and NVIVO training. A six-phase framework in data analysis was used to interpret the data [15] and each thematic analysis was completed independently by the two coders. Firstly, they read and re-read the transcribed manuscripts and began highlighting important comments made by the participants. Once familiarisation occurred, codes began to be identified by placing similar quotes into folders named under a code name. No specific pre-set questions were made to set codes around and all the data sets was coded. Thirdly, the codes were then organised into themes based on similarities amongst the codes identified followed by the fourth stage of reviewing the themes against the codes and the full data set. Further refining occurred as stage five which also involved defining and naming each theme, and then finally 
participants' quotes were extracted to best illustrate the themes. Evidence suggests saturation may occur at the sixth interview [16] so the two coding researchers independently began to check saturation from the sixth interview onwards within the coding stage of the data analysis by checking at which interview codes were identified against a log of codes. Once no new codes were identified, data saturation was determined.

The two coders met collectively to discuss the analysis, results and thematic titles. Differences, which were few, were discussed by referring to the data and the framework [15]. The two coders then finalised extracted quotes from participants to best describe the themes and ensure all voices were heard. If consensus between the two encoders was not reached, a third researcher would have been approached to resolve the issue, however that was not required. Respondent validation of the themes generated was not able to be conducted due to restraints within the project funding and participants being difficult to follow up in a timely manner due to geographical distance. It is acknowledged that results from this study were not able to be member checked.

The following steps were taken to foster reflexivity by the research team in attempts to achieve neutrality: the research design involving multiple researchers (two coders, separate interviewer and two additional staff on the research team) allowing reflective dialogue between team members, fostering the ability to reveal and contest any hidden beliefs or values which may have influenced the data analysis. The research team has a combined 30 years' experience working in the field of HNca treatment and rehabilitation, in a number of hospitals in Australia across three different states, giving the research team a broad understanding of the nature of general patient experience and outcomes following HNca treatment. Field notes from the interviews were collated. Additionally, a number of documents were maintained by the team to journal the research process including minutes of discussions at team meetings. Coding notes were also kept to track thoughts and decisions regarding themes as a form of reflexive journaling.

\section{Results}

The primary objective of this study was to investigate the views and experiences of the rehabilitation process of patients who undergo treatment for dysphagia post HNca. Data from semi-structured interviews were utilised to investigate this. Nil repeat interviews were conducted. Twelve potential participants were approached and only one declined due to feeling they could not talk well enough for an interview. Three other participants volunteered to participate verbally but eventually were not recruited due to data saturation being met.
Eight participants were therefore interviewed with a mean interview length of $52.5 \mathrm{~min}$ (32-71). The data provided rich detail on different experiences with the rehabilitation journey. Table 1 outlines demographic details. Six males and two females were recruited with a variety of $\mathrm{HNCa}$ oncological sites and all received surgical intervention with one participant receiving adjunct radiotherapy. Mean length of service in outpatient rehabilitation (i.e. time spent from admission to discharge from outpatient rehabilitation services) was 14.8 weeks (4-31) and mean number of $30 \mathrm{~min}$ sessions across all Allied Health disciplines was 16.6 (9-30). Both coders agreed that no additional new codes had been attained according to their logs by interview 6 . Interviews 7 and 8 had already occurred and the codes occurred in these interviews were not new but quotes were used from these participants to continue to illustrate the themes.

We asked which symptoms associated with HNca our cohort experienced and results are outlined in Fig. 1. Weight loss, difficulties swallowing, phlegm in throat and communication issues were the predominate difficulties experienced by over two thirds of participants. All symptoms, apart from shoulder or back pain, were reported by our cohort. Three participants reported "other" symptoms not on our checklist which were oral thrush, constipation and fatigue.

Six key themes were identified by the two encoders from thematic analysis of the interviews with underpinning subthemes (Table 2).

\section{Supportive Network is Essential}

Participants described the importance of having a network of supports from a range of sources as a key benefit to their rehabilitation process. Within this theme, two subthemes were identified. The first subtheme, community, consisted of networks that were already present, while some participants valued the connections they made with others who had similar experiences under the subtheme peers. One participant summed up the importance of a network by saying:

...I think it's much easier to deal with things when you feel that there's a whole team fighting the battle with you. - Participant 1.

\section{Community Supports (Family, Friends, Work)}

This subtheme included family and friends providing both practical and emotional support as well as work colleagues. Those within the greater community were also identified as sources of support.

You need people around you. You need all the support you can get...It's actually been rather interesting for me, because when this happened I cannot believe the level of support I got...It was just everybody. 
Table 1 Participant demographics

\begin{tabular}{|c|c|c|c|c|c|c|c|c|c|}
\hline \multicolumn{3}{|c|}{ Personal data } & \multicolumn{3}{|l|}{ Rehabilitation details } & \multicolumn{4}{|l|}{ Cancer details } \\
\hline & Age & Gender & $\begin{array}{l}\text { Disciplines } \\
\text { involved in rehab }\end{array}$ & $\begin{array}{l}\text { LOS in rehabilita- } \\
\text { tion }\end{array}$ & $\begin{array}{l}\text { Total number of } \\
\text { sessions ( } 30 \\
\text { mins) used in } \\
\text { rehabilitation }\end{array}$ & Location & Stage & $\begin{array}{l}\text { Surgery per- } \\
\text { formed }\end{array}$ & $\begin{array}{l}\text { Concurrent } \\
\text { therapy }\end{array}$ \\
\hline 1 & 55 & M & RC, SP, DT & 5 weeks & 8 & (L) oropharynx & $\mathrm{T} 2 \mathrm{~N} 1$ & $\begin{array}{l}\text { Neck dissection, } \\
\text { TORS (L) radi- } \\
\text { cal oropharyn- } \\
\text { gectomy }\end{array}$ & Nil \\
\hline 2 & 64 & M & RC, SP, DT & 5 weeks & 12 & (L) tonsil & T1N1 & $\begin{array}{l}\text { (L) neck dissec- } \\
\text { tion, TORS (L) } \\
\text { tonsillectomy }\end{array}$ & Nil \\
\hline 3 & 73 & $\mathrm{~F}$ & RC, SP, DT & 17 weeks & 12 & Vocal fold & T1a & $\begin{array}{l}\text { Bilateral neck dis- } \\
\text { section, salvage } \\
\text { total laryngec- } \\
\text { tomy }\end{array}$ & Nil \\
\hline 4 & 55 & M & RC, SP, DT, PT & 28 weeks & 25 & (L) tonsil & $\mathrm{T} 2 \mathrm{~N} 2 \mathrm{~b}$ & $\begin{array}{l}\text { (L) neck dissec- } \\
\text { tion, (L) TORS } \\
\text { oropharyn- } \\
\text { gectomy and } \\
\text { pharyngoplasty }\end{array}$ & Radiotherapy \\
\hline 5 & 59 & M & RC, SP, DT & 4 weeks & 9 & (L) tonsil & T2N1 & $\begin{array}{l}\text { (L) TORS radical } \\
\text { oropharyngec- } \\
\text { tomy + pharyn- } \\
\text { goplasty, (L) } \\
\text { neck dissection }\end{array}$ & Nil \\
\hline 6 & 75 & M & RC, SP, DT & 31 weeks & 16 & (L) tongue & T1N0 & $\begin{array}{l}\text { (L) partial glos- } \\
\text { sectomy and } \\
\text { flap reconstruc- } \\
\text { tion }\end{array}$ & Nil \\
\hline 7 & 60 & M & RC, SP, DT, Psych & 9 weeks & 21 & (R) tongue & T2NO & $\begin{array}{l}\text { salvage TORS and } \\
\text { flap reconstruc- } \\
\text { tion }\end{array}$ & Nil \\
\hline 8 & 51 & $\mathrm{~F}$ & RC, SP, DT, PT & 19 weeks & 30 & (R) soft palate & T1N0 & $\begin{array}{l}\text { Radical resection } \\
\text { of soft palate } \\
\text { with flap recon- } \\
\text { struction }\end{array}$ & Nil \\
\hline
\end{tabular}

$L O S$ length of service, $R C$ rehabilitation consultant, $S P$ speech pathology, $D T$ dietetics, $P T$ physiotherapist, $P$ sych psychology, TORS transoral robotic surgery

Even my dog groomer and my hairdresser both volunteered to help. I thought, that's something else.

- Participant 2.

...most of us...in a verbal environment, only absorb $20 \%, 30 \%, 40 \%$ of what's said. If you've got someone with you...my wife came to all the appointments... That's always helpful, to have someone there to pick up on the things you possibly missed. - Participant 4. I'm very lucky. I have a supportive set of colleagues, a couple of whom had cancer as well. So I've supported them in their battle with cancer. Then it was their turn to support me...I don't think people should underestimate the value of sharing their experience with other people and making an effort to maintain those connections...things like that are really important so you don't feel isolated and you feel part of a network. Participant 1.

\section{Peers}

A number of participants also discussed access to peer support as beneficial. Some participants described relationships formed with other patients with similar diagnoses during their inpatient stays, which continued to act as supports after discharge during the rehabilitation phase.

...he happened to be having his operation a day ahead of me, and we just bumped into each other in the hallways...I thought, oh I'll catch up with him... I bought a scrabble board and we played a bit of scrabble and 


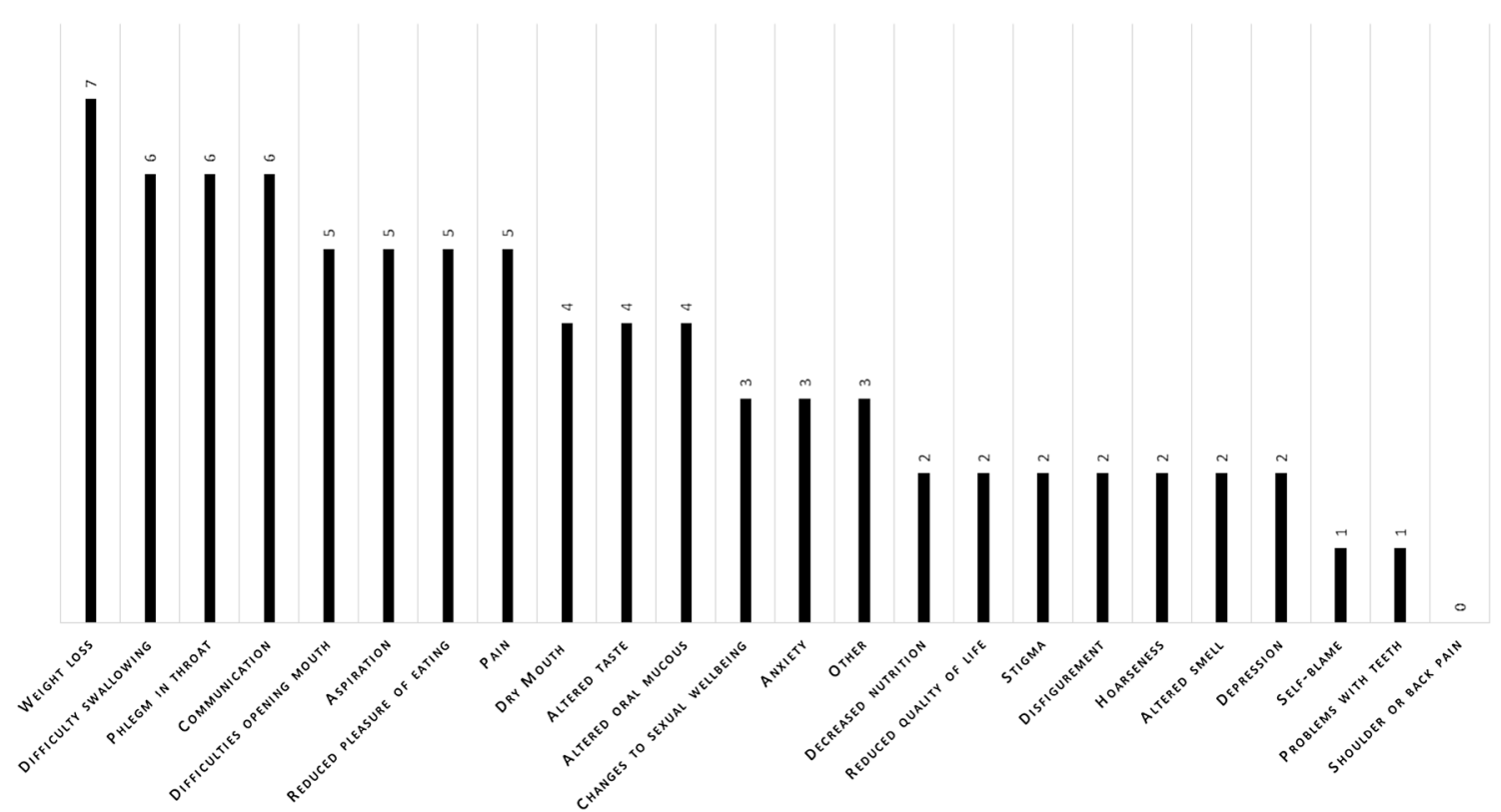

Fig. 1 Patient-reported symptoms

Table 2 Themes and subthemes

\begin{tabular}{ll}
\hline Themes & Subthemes \\
\hline Supportive network is essential & Community supports (family, friends, work) \\
& Peers \\
Reassurance from staff professionalism & Professional opinion \\
& Staff empathy \\
& Clear communication \\
& Holistic care \\
Access to service & Timing \\
Using own motivation and resilience & Communication \\
& Motivation \\
Receiving the right information & Self-resilience \\
& Understanding nature of symptoms \\
Ongoing shock and adjustment & Education at each stage \\
& Tailored information \\
& Shock \\
& Feeling fortunate \\
& Concerns regarding recurrence \\
\end{tabular}

went and had a few coffees...it was really good...it was very helpful - Participant 1 .

Another participant described the benefits of accessing organised peer support groups.

Everyone comes up with their own ideas. That's what the lary meeting is good for. You pick up a few little tips. - Participant 3.

\section{Reassurance from Staff Professionalism}

The professionalism provided by staff working with the participants was considered by many of the participants as a key component of good care and as a result provided the participants with a sense of reassurance. Four distinct staff behaviours were identified in this area: professional opinion; staff empathy; clear communication and holistic care.

\section{Professional Opinion}

Participants reported value in the feeling that staff had the appropriate skill and expertise to lead their rehabilitation towards success.

It is a slow process. I guess you've just got to keep the faith that the path you're on, set by the people that 
know, will get you through. A lot of trust involved... - Participant 4.

...I just felt right from the word go that the information I was given, the conversations that I had-the professional conversations - and the kind of engaging way they were done...there was always this air of calm and professionalism. It wasn't offhand. - Participant 7.

...I did get the impression [the physiotherapist] knew what he was doing and knew how all the muscles worked in the mouth and what was going on and what had to be achieved and how to go about doing it. So I was confident then...it worked well in the end. - Participant 8 .

\section{Staff Empathy}

Empathy and compassion from staff was strongly identified as a positive contributor to recovery at all stages of rehabilitation. Participants felt they had established relationships with the therapists and this development was a key positive component in their care experience.

...the two people I worked with here were able to establish empathy and that connection. I would just perhaps remind practitioners that that's probably number one, that people are probably going to be more honest and more open if they feel that there's a connection. - Participant 1.

..there was a genuine feeling of kindness and consideration and caring, which I think is one of the most important things of all when you're in that position. - Participant 2.

Everybody seemed...to have interest in what I was going through. Everybody seemed to have something of value to offer me. - Participant 4.

I felt right from the word go that we were in good hands... - Participant 7

\section{Clear Communication}

From the data, clear communication was identified as a key contributor to a positive rehabilitation experience.

...I felt my contact with the people here, I felt that was very supportive as well. I guess the nature of the job means that you've employed good communicators who have a strong sense of empathy, without eroding people's independence. - Participant 1.

Hospital staff were also identified as key parts of the supportive network to aid recovery, particularly as participants felt they were able to contact staff with any concerns or questions throughout the rehabilitation phase. This contact could be made formally through face to face appointments or informally via phone or email.

...if I need help that's definitely been there, there hasn't been a problem with that. - Participant 3

...I remember [the speech pathologist] was very insistent that if I had any questions, to make efforts to contact. I think everybody through the process had said that we're available if you have questions. - Participant 4.

It's all been very supportive all along...If you email them they email back nearly straight away. They've been fabulous. - Participant 3 .

....any questions I had would be answered. I know that if I still had questions, that I could approach members of the team if I wanted to. - Participant 7.

\section{Holistic Care}

Participants reported the importance of feeling they had been treated as a whole person as opposed to in individual parts.

...they were very professional in the way they established what capacity I had. They did a whole range of checks to see my...mental wellbeing and my physical wellbeing...From memory they discussed what sort of support I had at home, and whether I was accessing adequate food and drink... - Participant 1.

I don't think there's really much you could do. Everything has been done. I mean we couldn't ask for more than what we've had. - Participant 3.

...the whole experience...I can't think of anything that was bad. If there's nothing bad, I really couldn't see how to fix...Everybody seemed to have something of value to offer me. - Participant 4.

Some participants identified that referral to therapies as required outside the standard speech pathology and dietetics (for example, physiotherapy or psychology) extended their rehabilitation treatment in the correct way to achieve their goals.

I guess the staff are trained enough here that again they would ask enough questions to get you through to the right people. - Participant 4.

...I had a session with the psychologist. Which was good...So it's really a package of care, which I've really appreciated.[The hospital] need to be commended on that. - Participant 7.

...I would consider [speech pathology] to be the drivers to get me to [physiotherapy]... So that was where I felt confident with what was happening... - Participant 8 . 


\section{Access to Service}

Participants commented on their ability to access the rehabilitation service as required. Overall, two subthemes were identified, one related to timing and another with regards to the communication.

\section{Timing}

All participants interviewed felt their rehabilitation was initiated at an appropriate time following or during their treatment.

I think when you leave hospital I guess you need a certain period of adjustment when you get home before you're really ready to go down the rehab path...I guess you also need to allow some healing to take place before you can start to work on that. I think the timing was about right really. - Participant 1.

I think it was all quite timely...I don't remember it being too often. I don't remember it being too long between visits. Everything seemed normal...they asked questions...to see where I was going, and made an assessment as to where I should come back from there. - Participant 4.

....it was good...because I wasn't going back to see the doctor for three months... You really want a bit of follow up. To some extent, the speech pathology follow up met that need of the surgery follow up in a shorter period of time. Which I thought was quite handy. - Participant 5.

Most participants identified the start of their rehabilitation commencing immediately post-surgery, even while still in the acute hospital and continued through the outpatient phase, despite our service delivery model being more across these phases with different teams of clinicians for inpatient and outpatient treatment.

I think the last day or two when I was in hospital, because then it was to that point that I'd decided that I have to do something about this. There's no choice B. - Participant 2.

...from day one really. Because you start straight away. So, you really learn most of the things pretty quickly - Participant 3

...it was the next day...the speech pathologist...came in and started to speak to me...It was all right from the word go. I felt very comfortable with that...So the rehabilitation started from the word go. It was very positive and uplifting. - Participant 7.

It was identified by one participant that if an additional service was required, for example psychology support, this was time sensitive. The rehabilitation team needed to be reactive to the participants' needs and if service was delayed it would be of less value.

...the only problem that I had was when I came off the medication the second day in, I crashed to earth and I was in a really, really bad way. Terrible depression... psychology here were supposed to contact me and line something up... [the speech pathologist] just also followed that up and so did [the surgeon]. Nobody contacted me for another-I think it was two, three weeks later. By then I was off and running. - Participant 2.

\section{Communication}

Good communication within the team and to the participant were positive contributors to the participants' experience.

...the speech pathologist...dietitian, I thought that worked very well in concert to go through all the questions that needed to be asked and just establish where I was at and what needed to be done after that. So I was quite happy with it. - Participant 1.

At times, perceived communication breakdown within the team was met by frustration from participants.

I suppose for me...there's sort of borders for the specialists, but there's no borders for me as the client going through it... So if an issue...pops up when I'm talking to one of those specialists and it's not their area, then no, you need to ask so and so this...I'm thinking just give me some answers... - Participant 5.

\section{Using Own Motivation and Resilience}

It was clear in the interviews that the participants did not only gather strength and resources from their supportive personal networks and from their professional team but also from within themselves. This comprised a key component of their rehabilitation and recovery. Both motivation and resilience appeared to be key factors in their experience.

\section{Motivation}

Multiple participants identified themselves as major drivers of their rehabilitation, not only from a motivation perspective but also in relation to taking initiative in progressing with their recovery of oral intake and nutritional outcomes.

...I was so determined that I kept on challenging myself and upping it and upping it and upping the type of foods that I was managing...I just thought I had to do it for myself. Everybody's different. I think some people need more coaching and I've always been very, 
very focused on everything I've done, so I had that advantage. - Participant 2.

Then on the second meeting they were pretty happy that my progress was good, my weight was stable, and they really felt there probably wasn't a lot more they needed to do, that I'd reached a point where my recovery was going to be self-propelled. - Participant 1 .

Well, the question I'm asking myself is what did I expect or what could have been done that wasn't done? There isn't really...it was pretty much - like it's my swallowing, and my chewing, and my eating. No one else can manage it. - Participant 5.

\section{Self-Resilience}

Participants described a resilience and determination intrinsic in their personalities as a significant strength in dealing with their diagnosis, treatment and rehabilitation.

Not everybody's the same...I will bounce back. I will fall flat on my face and dust myself off and keep going, but not everybody's like that. I know that. - Participant 2.

...I've always believed the next day is a better day. I always have learnt to sleep on things, and always the next day is a better day. You just get through. - Participant 4.

I think this is a part of that it's really rely on myself to overcome that...I think, at this stage, I don't think I'm in the state I need to seek outside help. Just I try to help myself...I have to help myself to encounter such challenge. - Participant 6.

They can manage things themselves...it's sort of empowering people to take some action. - Participant 5.

\section{Understanding Nature of Symptoms}

Participants identified that some post-treatment concerns had not been resolved, but demonstrated an understanding that it was part of the nature of their treatment and disease to have some ongoing symptoms. Participants felt these issues would need to be managed long term and the majority felt confident in their ability to do so.

...now I'm comfortable and I'm eating well and I don't feel restricted in any way, so I've been a bit slack with the exercises I'm supposed to be doing at home and everything, but I think that's because I'm comfortable with where things are at now and if it progresses slowly from here on...it's not a bother to me. - Participant 8.

Teach me how to go out, so people can hear me and don't have to write on a board, and eat and talk when
I've finished, because that's about the only thing that I have to [laughing]... When I go to tennis, I just sit there and every now and then I start talking and they know to be quiet. It's mainly restaurants and that kind of stuff; it's difficult... So, the rehab can't cure that I don't think. - Participant 3.

My life is different, but...- it's just - it is what it is, so to speak...having done all that, what I'm left with... I don't think any exercises - or maybe particular techniques, if I employed them all the time, would do that. - Participant 4.

Talking and eating is more... difficult again. So restaurants and things like that end up being a bit trickier, but not hugely...I can live with that for the rest of my life. It's not the end of the world. But, I'm hoping it will continue to get a little bit better. It has got a bit better. - Participant 5.

It was more about making sure I...re-established my ways of eating...I possibly never will be, completely back to where I was. I'm okay with that, that's fine. Participant 6.

I'm fine now. I'm perfectly comfortable in my day-today life. All of the problems, I guess in inverted commas, they're only little. Like the phlegm in the throat, it's not like there's a-I'm not drowning back there, it's just a little bit. The speech issue; it's not a major thing, it's just that I'm conscious of things being slightly different now. The altered smell, even if that's something I have to put up with, it's not a massive issue. I can still smell...I'm happy enough to live each day and no, there's no big inconveniences... - Participant 8.

\section{Receiving the Right Information}

Participants reported that receiving the right information constituted a better care experience. The two subthemes in this area relate to receiving the relevant information at the right time (throughout the whole journey) and also that the information was tailored to the participant and their needs.

\section{Education at Each Stage}

Many participants identified the importance of education prior to treatment and during their rehabilitation, with varying experiences and opinions of the quality of this education.

...I would have benefitted from some sort of counselling beforehand, because there was a lot of things that I really wasn't prepared for... when I got out of surgery...it was far worse that what I anticipated. Participant 2.

...if you're having a sort of surgery and you're not going to be able to communicate clearly... it would 
be good to know that at the start so you can make some arrangements with people and you've got a bit of time... What would have been really handy would have been a lifestyle pamphlet...It's pretty hard to go through rehabilitation properly if you're stressed off your brain because your work hasn't been done...Participant 5.

...I felt as if...all information was given. I understood what was going to happen. I understood that the outcome would be good. - Participant 7.

There were no surprises and the attention afterwards was good as well, so there wasn't any surprises. Participant 8

They felt knowing what to expect at each stage of their treatment and rehabilitation was important to getting the most out of their therapy.

...ensure that the patient can see a clear pathway that they're going to travel down, so that they understand the sequence of steps that will take place as their treatment unfolds. - Participant 1.

...if I was redrawing it now...I'd like to have had [education] up front...I wouldn't have shied away from it...I would have fared better knowing that things were going exactly as they were supposed to go. It was brutal, extremely painful and then it... starts to get better...If you're not prepared for it... it's very hard to get your head around it that this is a temporary process. - Participant 2.

We all have busy lives and we all have plans and things we've got underway. To understand what the implications of this are on that, would be very handy for patients. - Participant 5.

Some participants found written material most helpful while others were ambivalent about written handouts and identified reiteration of verbal information as their preferred method of receiving education.

...having access to the information you can go back to and refresh your memory of it, has been really helpful. - Participant 3

...I got some handouts...I guess I tend to read things once and put it aside, and don't go back to it and refer to it. I possibly could have....read the documents more often and followed the instructions better, but what I did seemed to work. It seemed to be enough. - Participant 4.

...I don't think I got any written information. I don't remember feeling I needed it. I guess if anything was relevant, I would've been happy to see it in writing, but I don't think I missed it. - Participant 8.

\section{Tailored Information}

The main feedback regarding education was the importance of tailored information specific to their situation over generic information.

...people are adults, they run their own lives. In a lot of cases they don't need to have things done for them, they just need to be provided with the right advice and information, and that can be done in a fairly simple sort of way that doesn't take extra time. - Participant 5.

Post-operative pain management was an area where specific information was required and multiple participants felt this could have been managed better in their recovery.

The problem was I guess no one really had explained what would be normal. So you endure a lot of pain thinking, well maybe this is just what it is... - Participant 1.

Learnt how to manage my pain...it wasn't until I actually scheduled out the painkillers, wrote it down what time I should take them...I thought, right, I've got to do something about this...trying to eat something, I'm in agonising pain. There's my wife and my [children] looking at me in sheer horror...I thought, I've got to get this pain management right. - Participant 4.

I had about three different sorts of painkillers taken at multiple different stages between them...I ended up in a fair bit of pain because I botched it up...it was just too many things to remember... a tablet box, which would be really handy. Or just some advice. - Participant 5 .

\section{Ongoing Shock and Adjustment}

Participants reported that even though the rehabilitation period was completed they still were experiencing emotions from what had occurred. This was not only represented through expressions of ongoing shock, but also feelings of gratitude that they had received treatment for the disease and also concerns about possibilities of a recurrence.

\section{Shock}

Participants continued to discuss the adjustment to their diagnosis even after rehabilitation was completed. This idea continued to be at the forefront of their relayed experience when being interviewed, despite all participants completing their entire treatment.

It's always a bit of a shock I think for most people to suddenly find you've got a cancer diagnosis...I guess everyone thinks that it's not going to happen to them and suddenly it does. - Participant 1. 
I'm very healthy, I mean ridiculously healthy. I'd had all my blood tests done prior to this...I got tested for virtually everything... So this is a bit of a surprise for me. - Participant 2.

The fast pace of the journey from diagnosis to treatment and then to rehabilitation was also recognised by participants, which potentially contributes to their discussion of the ongoing shock about the way in which their experience has affected their lives in the long term.

....so I went to the doctor...got into to see the specialist...it was just like a whirlwind. It was very, very fast... While I'm sitting there, he was on the phone to the surgeon saying I've got one here. He needs to come and see you straight away...straight into town...here are your options: radiotherapy or surgery.... it was very hard to make a decision because you don't have all the information and I probably discovered a lot more later on. Because it happened so quickly. - Participant 5.

\section{Feeling Fortunate}

Although participants continued to describe the shock of a cancer diagnosis, there was discussion of the fortunate feelings from some aspects of their treatment and rehabilitation care.

I feel very lucky in that a) I got this cancer at an age when they had the robotic surgery available. So I think two years ago it would have been a much more complicated procedure. I guess if there's a positive about it, that the later you have these illnesses, the better variety of treatments available... So yeah, I think I've been pretty lucky. - Participant 1.

No, life is still good. Life is very good and I have to admit, life has been far better for me than it has been for a lot of other people...in some respects I've had an absolutely blessed life...I could not have asked for more out of life. - Participant 2.

I wouldn't consider myself an optimist but it very clearly came out to me how lucky I've been right through that. Even if [the cancer] has come back, there's still another option for things to do that I've got that some may people wouldn't have. So I feel very fortunate in that way. - Participant 5.

\section{Concerns Regarding Recurrence}

Participants also described their concerns regarding potential cancer recurrence as an ongoing worry.

I'm philosophical about it. There's no guarantee that something won't recur. There's no guarantee I'll get a totally unrelated cancer...it's quite possible I'll get run over by a tram... You can't worry about it. You'd never leave the house. - Participant 2.

The thing that is I suppose a bit of a dilemma-so it's a cancer...I don't know whether it's gone. No one sort of knows whether it's gone. I go back in for a PET scan... If we find something, you're having more. If we don't find anything, I don't quite know what it is. So I'm not quite sure what the future holds in terms of the monitoring. But I really don't have a feel for that. Maybe the surgeon doesn't either. - Participant 5.

...[I] do feel a little bit of a heightened sense of anxiety about the fact that I've had two goes at this...I didn't expect this to happen, and it did. That's the type of anxiety. I sometimes dwell on that a little. Not a lot. But sometimes I do. - Participant 7.

...the biggest worry for me was the cancer and I thought well, the cancer's out, so that was my biggest concern. So that weight was off...my shoulders and the big concern was, will it come back... - Participant 8 .

\section{Discussion}

The aim of this study was to investigate patients' perceptions on what makes a better care experience while undergoing treatment for oropharyngeal dysphagia secondary to HNca. Eight participants who had completed a rehabilitation program following dysphagia after treatment for HNca were interviewed. From the interviews six themes were identified. Three of the themes (Supportive network is essential, Using own motivation and resilience and Ongoing shock and adjustment) were identified as being themes which evolved from experiences outside of the rehabilitation setting. On the other hand, the remaining three themes (Access to service, Reassurance from staff professionalism and Receiving the right information) are associated with experiences interacting with the HNca service.

Messing, Ward [8] indicate that evaluating a process through the eyes of the patient is essential to identify strengths, opportunities and limitations. Despite the importance of this, there is a paucity of data from patient centred research as to how to provide a better care experience. In this current study, we have presented data from patients which has highlighted what makes a better care experience. These were identified as internal and external responses as outlined above. These results support discussions in Jacobson [17] that in the current cancer survivorship orientated era, the experience a patient is provided with goes beyond pure treatment of dysphagia and malnutrition.

Previous systematic reviews and meta-analyses have been conducted into the lived experience of those with head and neck cancer $[3,18]$. It is acknowledged that the lived experience is different to our question on perceptions of the 
rehabilitation experience, particularly given our sample had varying aetiologies, treatments and past histories, especially a salvage laryngectomy whose lived experience would be different to other participants post-oral surgery. However, the themes were developed out of all responses from the participants to questions pertaining specifically to their rehabilitation journey and some of these themes are consistent with those found in the systematic reviews of the lived experience. Although two of the participants underwent salvage surgery for $\mathrm{HNCa}$ recurrence, the analysis of our data did not reveal an obvious difference in opinion regarding rehabilitation experience when compared to those participants undergoing primary treatment for HNCa. Lang, France [3] found in their systematic review and meta-analysis of psychological experiences that people with HNca developed supportive networks with family, health professionals and peers. This is consistent with themes in this study of 'Supportive network is essential' and 'Reassurance from staff professionalism'. Another theme in Lang, France [3] 'Finding a path' with components of that being developing effective self-care, taking an active role in their experience and developing certain mindsets, all of which align with this study's theme of 'Using own motivation and resilience'. Professional and peer support, along with coping strategies were also reported in the systematic review and meta-analysis which investigated the impact of nutrition on the head and neck cancer experience [18]. Lang, France [3] discuss that HNca causes a major disruption to people's lives but disruption was not a major theme in this study, most likely due to the fact that participants were retrospectively reflecting on their rehabilitation experience as opposed to data being collected at early stages during treatments.

Messing, Ward [8] explored the barriers and limitations for implementation and maintaining a multidisciplinary HNca clinical pathway. They concluded that whilst beneficial insights were made, in future studies patients' perceptions on this care model should be sought. While our participants did not experience this model of care, this study would support the collation of patient perceptions into service delivery as essential. There was no indication within our data that participants wanted a structured pathway and they valued being able to contact staff when they wanted, however they were not directly asked to comment on certain models of care. Participants were asked "If your rehabilitation could have been any way you wanted it-what would the service have looked like?" This was particularly difficult for participants to consider and formulate care pathway models independently.

Some participants identified that referral to therapies as required outside the standard speech pathology and dietetics (for example, physiotherapy or psychology) extended their rehabilitation treatment in the correct way to achieve their goals. The participants reported concerns also about recurrence in the future and the shock of diagnosis, which are related to mood and feelings of anxiety. It is noted that despite all being offered psychological services, only one accessed the service. Although not discussed in the interviews, it would be useful to know whether concerns about recurrence and adjustment to diagnosis could have been managed better with access to psychological support therefore enhancing the care experience. It may be that their own resilience and motivation, the support they received from other staff and from their social network, supported them at times but it is unclear from this study how professional psychological support could reduce the distress. One other reason for the lack of psychology uptake may be that patients at this stage of the recovery are more focused on the physiological impact of the disease, as the symptoms which more participants reported were physiological in nature, with the psychological aspects less reported by the participants.

This research indicates that patients value a supportive network as a contributing factor for a better care experience. A supportive network was described by participants as being family and friends (their community) and peers with similar diagnoses. Vakharia, Ali [19] found that a peer support group for patients with HNca improved quality of life. Participants reported that peers provided them with practical strategies and tips for managing the functional implications of their dysphagia and that the relationships formed with other patients with similar diagnoses acted as psychological support. Therefore, it would be advisable that as part of the treatment plan, patients are counselled on how to access peer networks if desired.

Furthermore, given the importance of family support, it would be advisable that family are also provided information and have access to education on how best to support their loved ones and themselves. Simpson, Dall'Armi [20] found that psychological stress in carers of patients with HNca was elevated and that clinically health providers could screen for resilience in carers. It is therefore hypothesised that if carers are better resourced and informed, then they can be an even stronger support for the person with HNca.

All participants interviewed felt their rehabilitation was initiated at an appropriate time following or during their treatment. Most participants identified the start of their rehabilitation commencing immediately post-surgery, even while still in the acute hospital and continued through the outpatient phase, despite our service delivery model being more separated across these phases. Most participants reported that they needed some time at home to adjust and work out things for themselves. The only exception to this was when pain was perceived as intolerable. Some participants reported not knowing how bad the pain would be before their surgery.

A further recommendation in this field has been to increase patient education in order to prepare patients for 
potential post-treatment swallowing and communication symptoms [2, 4]. Many participants identified the importance of education prior to treatment and during their rehabilitation, with varying experiences and opinions of the quality of this education. Some participants found written material most helpful while others were ambivalent about written handouts and identified reiteration of verbal education as their preferred method of receiving information. Overall, the participants expressed the desire for education to be specific to their needs, which is not surprising given the variety of symptoms the participants reported on the symptom checklist. This is supported by Brockbank, Miller [21] who found, after studying the current content, format and style of presentation of information and education given to patients, that patients vary in what they need. Some participants appeared to want holistic education including at the pre-operative stage so they could make preparations in a variety of aspects of their life. However not all participants reported this, so education and counselling should be patient-specific and available at any point of their care pathway. As per Fig. 1 symptoms are varied and there is no consistent pattern, therefore clinicians need to be able to respond and assist with any symptom associated with $\mathrm{HNca}$ as required or refer early to another specialty. The participants in this study appreciated further referrals to other disciplines which could assist in their rehabilitation.

\section{Clinical Implications}

Already in the discussion some clinical implications have been outlined. These include peer support, access to a multidisciplinary team with psychological support, tailored information and supporting the support partners. Additional to these, there are other implications for clinical practice.

The participants valued being treated as a person and receiving a holistic approach to their treatment. Despite being referred into the service for dysphagia rehabilitation and receiving dysphagia rehabilitation, participants did not focus a lot on discussing the components of their dysphagia rehabilitation. Instead they reported that being treated in a holistic manner, not just having dysphagia, was a key priority for them and this added positively to their experience. This is consistent with other reporting in the literature which states clinicians need to apply holistic assessment and management of patients with HNca to not only address physiological impairments but also associated emotional and psychosocial aspects of dysphagia post HNca [22]. Participants reported one of the ways this was done was through staff professionalism, especially their style of communication and open questioning. Clinically, this means that staff need to ensure that they are trained and able to implement these essential skills and that they have sufficient resources and time to provide a holistic approach. One way to ensure holistic care and to ensure all relevant areas may be to use a questionnaire such as The Brief Rehabilitation Assessment for Survivors of Head and Neck Cancer (BRASH) [23] or the head and neck symptom checklist $\odot$ [24]. This could be used by the initial treating team member. In our model, patients see a rehabilitation consultant to co-ordinate care. It may be valuable as part of their role to administer some of the suggested questionnaires to ensure a holistic approach to enable better rehabilitation planning. If a rehabilitation consultant is not part of the team, it had been suggested that another clinician who is experienced in HNca care takes on the responsibility of planning the rehabilitation care [23]. Such thorough questioning and planning may allow better treatment of symptoms, which, as we have described above, can be varied and very patient-specific.

The participants demonstrated their own resilience and sought non-professional support (family, friends and peers) to manage their symptoms and experience. This was a particularly valuable skill for the group to have even though the participants still continued to value clinical expertise. Given the importance of resilience and non-professional support, it would be valuable to screen for this and intervene if necessary. Furthermore, participants reported that symptoms continued despite mutual agreement with clinicians to leave rehabilitation. Given ongoing symptoms and patients reporting willingness to use their own determination and skills yet still valuing expert opinion, it is prudent that on discharge patients should feel that they can continue to contact their clinicians and that the pathway is open and welcoming to return whenever needed.

Given that the participants in this study valued staff who were good communicators, demonstrated empathy and were experts in their field, it is essential that service providers support education, resources and training in these areas for their clinicians. Not only for new staff to the HNca field but also experienced staff so that compassion fatigue can be managed and that the staff stay ahead of the ever evolving nature and treatment of HNca. Given the ongoing psychological burden and the importance of resilience in the recovery phase, clinicians may focus on counselling skills and being able to identify and support resilience in this population.

\section{Future Research Implications}

Six of the eight participants reported communication issues however the research was predominantly focused on participants with dysphagia. There is opportunity for research to focus more on patient perception of communication deficits post $\mathrm{HNca}$, especially given that clinical and patient perceptions are known to differ [25]. 
We only looked at retrospective perceptions aimed at investigating the rehabilitation experience although participants chose to reflect at times on their acute and pre-operative experiences. Patients' perceptions can vary widely from diagnosis to follow-up treatment, with each stage potentially affecting the patient's perceptions [10]. Future research may investigate perceptions at each stage in greater detail including the diagnosis and pre-operative stage, especially given that our research shows that the shock of diagnosis continues to persist for many months. Additionally, our population were mostly surgically treated for their cancers. It would be worthwhile gathering further perceptions from people undergoing radiotherapy as their primary treatment modality.

Furthermore, while the symptom checklist enabled us to understand the cohort's symptoms better and provide some framework to enable discussion, it had some limitations when in use. The optimal way to use such a checklist to further explore the HNca experience would be valuable knowledge. Future research may be valuable to gather perceptions on how each symptom was managed and to gather patient generated solutions and ideas on how to manage these. Also the choice to use a more validated symptom checklist such as the head and neck symptom checklist $\odot$ [26] may be a way of collating further data with survey-based methodology.

Finally, it is recommended that compassion, wellbeing and empathy training is completed by staff working in this area as it was reported by the participants to be extremely well valued and essential to the care experience. Future research may evaluate which model of training can improve patient perceptions of care, as well as evaluate the clinicians' capacity to support the patient through their care journey.

\section{Limitations}

The study occurred in only one service and participants were not asked about other services or whether they had experience at other services. Therefore, these results need to be taken in context of the environment the research was conducted in; a large non-for-profit private multidisciplinary healthcare setting. Overall, our participants had good swallowing outcomes with none being enteral feeding dependent. As a result, we did not capture the perspectives of those who did not have good outcomes. Collection of more formalised outcomes of swallowing, and communication, may have been used to correlate qualitative data with quantitative outcome data. Furthermore, due to a small number of participants and variety within the cohort (tumour sites, staging, and adjunct chemo/radiation therapy) we were unable to subgroup participants and examine how different subpopulations may have different experiences and needs. Additionally the small number within the study did not allow further investigations into what support those suffering from different degrees of functional change may require. This may be worthwhile to do in future studies with larger cohorts and more selective participant profiles. Finally, the participants in this study were particularly young, mostly post-surgery and in a private health setting so may not be representative of the whole head and neck cancer population or rehabilitation experience therefore application of results may be limited to similar settings with a similar population.

\section{Conclusion}

This research has demonstrated that the collation of patients' perspectives are valuable to increase insight into what makes a better rehabilitative journey for patients with $\mathrm{HNca}$. Based on this research finding, rehabilitation care for patients with HNca should be holistic, specialised and person-specific.

Acknowledgements This research was supported by a clinician research grant awarded by Speech Pathology Australia in 2016 (award title: Clinician Research Grant, 2016). Thank you to our participants for sharing their experiences. We would also like to thank Margaret Mealings for sharing her interviewing expertise.

\section{Compliance with Ethical Standards}

Conflict of interest Authors Martin Checklin, Jessica Bain and Lucy Bath report no conflict of interests. Kate Lethbridge received a research grant from Speech Pathology Australia to conduct this work (Award Title: Clinician Research Grant, 2016) and has no further conflicts of interest. The authors alone are responsible for producing this paper.

Ethical Approval The study was completed in accordance with the ethical standards of the local institutional ethics committee (Epworth Healthcare, Ethics Number EH2017-189) and with the 1964 Helsinki declaration. This research was supported by a clinician research grant awarded by Speech Pathology Australia in 2016 (Award Title: Clinician Research Grant, 2016) to Ms Kate Lethbridge.

Informed Consent Informed consent was obtained from all participants.

\section{Appendix 1:Interview Script}

Interview One-Scene Two: The main interview.

When did your rehabilitation start for you?

How was your rehabilitation experience?

What do you feel were the most important things in your rehabilitation? Why is that?

What was done well during your rehabilitation?

Are there things you think could have been done better? Why is that? 
If we could wipe the slate clean and your rehabilitation could have been any way you wanted it - what would the service have looked like?

What is your advice to heath care providers who work with people with head and neck cancer?

Now I'd like to ask some specific questions [Tailoring wording with reference to what has already been said by participant].

The information you were provided during rehabilitation-how was it given to you? What was good about this and what could have been done differently?

Interview One-Scene Three: Presentation of symptoms.

I'm going to give you a piece of paper. On this, are symptoms which have been reported in the research on what people with head and neck cancer experience?

[Present paper, highlighter and pen with symptoms written on them] have a look.

I'd like you to highlight which symptoms you experienced.

Can you tell me about them?

Now, I'd like you to circle the ones which you felt were managed well while you were in the rehab phase?

Why were they managed well?

So the ones you didn't circle you feel could have been managed differently-why is that? What would you have liked done differently?

Interview One-Scene Four: Closing the interview.

Thank you. I have asked all my questions now. Is there anything you would like to add?

If there is anything you wished you had said after the interview, you may write it down and email it to us. The email is in the information sheet provided-would you like it again?

\section{Appendix 2: Symptom Checklist}

\section{Swallowing.}

Opening the mouth.

Chewing.

Dry mouth.

Altered taste.

Malnutrition.

Weight loss.

Aspiration (food going down the wrong way).

Reduced pleasure of eating.

Reduced quality of life.

Stigma.

Self-blame.

Changes to sexual wellbeing, intimacy and relationships.

Disfigurement.

Altered oral mucous (lining of your mouth and throat).

Hoarseness.
Phlegm in throat.

Shoulder or back pain.

Altered smell.

Dentition issues.

Anxiety.

Depression.

Malnutrition.

Speech/communication changes.

Pain.

Other

\section{References}

1. Larsson M, Hedelin B, Athlin E. Lived experiences of eating problems for patients with head and neck cancer during radiotherapy. J Clin Nurs. 2003;12(4):562-70.

2. Ganzer $\mathrm{H}$, et al. The eating experience after treatment for head and neck cancer: a review of the literature. Oral Oncol. 2015;51(7):634-42.

3. Lang H, et al. The psychological experience of living with head and neck cancer: a systematic review and meta-synthesis. Psycho Oncol. 2013;22(12):2648-63.

4. Nund RL, et al. Communication changes following non-glottic head and neck cancer management: The perspectives of survivors and carers. Int J Speech Lang Pathol. 2015;17(3):263-72.

5. Ottosson S, Laurell G, Olsson C. The experience of food, eating and meals following radiotherapy for head and neck cancer: a qualitative study. J Clin Nurs. 2013;22(7-8):1034-43.

6. McQuestion M, Fitch M, Howell D. The changed meaning of food: physical, social and emotional loss for patients having received radiation treatment for head and neck cancer. Eur J Oncol Nurs. 2011;15(2):145-51.

7. Sasaki CT, Leder SB. Comments on selected recent dysphagia literature. Dysphagia. 2015;30(4):482-7.

8. Messing BP, et al. Establishing a multidisciplinary head and neck clinical pathway: an implementation evaluation and audit of dysphagia-related services and outcomes. Dysphagia. 2019;34(1):89-104.

9. Cousins N, et al. A systematic review of interventions for eating and drinking problems following treatment for head and neck cancer suggests a need to look beyond swallowing and trismus. Oral Oncol. 2013;49(5):387-400.

10. Hanefeld J, Powell-Jackson T, Balabanova D. Understanding and measuring quality of care: dealing with complexity. Bull World Health Organ. 2017;95(5):368.

11. Lebel $\mathrm{S}$, et al. The psychosocial impact of stigma in people with head and neck or lung cancer. Psycho Oncol. 2013;22(1):140-52.

12. Hadjieva T, et al. Treatment of oral mucositis pain following radiation therapy for head-and-neck cancer using a bioadhesive barrier-forming lipid solution. Support Care Cancer. 2014;22(6):1557-622.

13. Chaplin JM, Morton RP. A prospective, longitudinal study of pain in head and neck cancer patients. Head Neck. 1999;21(6):531-7.

14. De Boer MF, et al. Physical and psychosocial correlates of head and neck cancer: a review of the literature. Otolaryngol Head Neck Surg. 1999;120(3):427-36.

15. Braun V, Clarke V. Using thematic analysis in psychology. Qual Res Psychol. 2006;3(2):77-101.

16. Guest G, Bunce A, Johnson L. How many interviews are enough? An experiment with data saturation and variability. Field Methods. 2006;18(1):59-82. 
17. Jacobson MC. The experience of head and neck cancer survivorship (including laryngectomy): an integrated biopsychosocial model. Curr Opin Supp Palliat Care. 2018;12(1):65-73.

18. Bressan $\mathrm{V}$, et al. The life experience of nutrition impact symptoms during treatment for head and neck cancer patients: a systematic review and meta-synthesis. Support Care Cancer. 2017;25(5):1699-712.

19. Vakharia KT, Ali MJ, Wang SJ. Quality-of-life impact of participation in a head and neck cancer support group. Otolaryngol Head Neck Surg. 2007;136(3):405-10.

20. Simpson GK, et al. Does resilience mediate carer distress after head and neck cancer? Cancer Nurs. 2015;38(6):E30-E3636.

21. Brockbank $S$, et al. Pretreatment information on dysphagia: exploring the views of head and neck cancer patients. J Pain Symptom Manag. 2015;49(1):89-97.

22. Nund RL, et al. The lived experience of dysphagia following nonsurgical treatment for head and neck cancer. Int J Speech Lang Pathol. 2014;16(3):282-9.

23. McEwen SE, et al. Evaluation of a rehabilitation planning consult for survivors of head and neck cancer. Head Neck. 2018;40(7):1415-24.

24. Schmidt KN, et al. Validation of the head and neck patient symptom checklist as a nutrition impact symptom assessment tool for head and neck cancer patients. Support Care Cancer. 2013;21(1):27-34.
25. Constantinescu G, et al. Patient perception of speech outcomes: the relationship between clinical measures and self-perception of speech function following surgical treatment for oral cancer. Am J Speech Lang Pathol. 2017;26(2):241-7.

26. Kubrak C, Olson K, Baracos VE. The head and neck symptom checklist $\odot$ : an instrument to evaluate nutrition impact symptoms effect on energy intake and weight loss. Support Care Cancer. 2013;21(11):3127-36.

Publisher's Note Springer Nature remains neutral with regard to jurisdictional claims in published maps and institutional affiliations.

Martin Checklin Master of Health Sciences, Master of Speech Pathology

Jessica Bain Bachelor of Nutrition and Dietetics (Hons)

Lucy Bath Master of Speech Pathology (Hons)

Kate Lethbridge Masters of Public Health, Bachelor of Applied Science (Speech Pathology) 